\title{
Mieloma no secretor
}

\author{
Jesús Ballano-Rodríguez-Solís ${ }^{1}$, Itziar Carmona-Zabala² ${ }^{2}$ Santiago Nieto-Llanos ${ }^{3}$, Jaime de Miguel-Criado ${ }^{4}$ \\ ${ }^{1}$ Servicio de Medicina Interna. Hospital Universitario del Henares. Madrid. España \\ ${ }^{2}$ Servicio de Hematología y Hemoterapia. Hospital Universitario del Henares, Coslada. Madrid. España \\ ${ }^{3}$ Servicio de Anatomía Patológica. Hospital Universitario del Henares, Coslada. Madrid. España \\ ${ }^{4}$ Servicio de Radiodiagnóstico. Hospital Universitario del Henares, Coslada. Madrid. España
}

Recibido: 11/10/2020

Aceptado: 20/11/2020

En línea: 31/12/2020

Citar como: Ballano-Rodríguez-Solís J, Carmona-Zabala I, Nieto-Llanos S, de Miguel-Criado J. Mieloma no secretor. Rev Esp Casos Clin Med Intern (RECCMI). 2020 (Dic); 5(3): 126-128. doi: 10.32818/reccmi.a5n3a10.

Cite this as: Ballano-Rodríguez-Solís J, Carmona-Zabala I, Nieto-Llanos S, de Miguel-Criado J. Non-secretory myeloma. Rev Esp Casos Clin Med Intern (RECCMI). 2020 (Dec); 5(3): 126-128. doi: 10.32818/reccmi.a5n3a10.

Autor para correspondencia: Jesús Ballano-Rodríguez-Solís. jesus.ballano@salud.madrid.org

\begin{tabular}{l} 
Palabras clave \\
\hline$\triangleright$ Mieloma no secretor \\
$\triangleright$ Dolor óseo \\
$\triangleright$ Aplastamientos vertebrales \\
$\triangleright$ Osteoporosis secundaria \\
$\triangleright$ Reacción leucoeritroblástica
\end{tabular}

Keywords

$\triangleright$ Non-secretory myeloma

$\triangleright$ Bone pain

$\triangleright$ Vertebral compression fractures

$\triangleright$ Secondary osteoporosis

$\triangleright$ Leukoerythroblastic reaction

\section{Resumen}

El mieloma no secretor constituye una forma excepcional de mieloma (1\% de los casos). Se trata de un subtipo que no presenta pico monoclonal ni en suero ni en orina. El estudio de cadenas ligeras libres en suero también resulta negativo. La fragilidad ósea y el dolor óseo, especialmente si asocian anemia, hipercalcemia e insuficiencia renal, orientan hacia su existencia.

Se presenta el caso de una mujer de 76 años con aplastamientos vertebrales y dolor óseo difuso, finalmente diagnosticada de mieloma no secretor en fase avanzada. De esta forma, se pretende concienciar sobre su existencia para un diagnóstico y tratamiento precoces.

Abstract
A non-secretory myeloma is an exceptional form of myeloma (1\% of cases). It is a subtype that does not present mono-
clonal gammopathy in serum or urine. The study of free light chains in serum is also negative. Bone fragility and bone
pain, mainly if associated with anemia, hypercalcemia, and kidney failure, suggest its presence.
We present a 76-year-old woman with vertebral compression fractures and diffuse bone pain, finally diagnosed with
advanced non-secretory myeloma. This case intends to raise awareness about a rare entity to make an early diagnosis
and treatment.

\section{Puntos destacados}

$\triangleright \quad$ La ausencia de pico monoclonal no excluye el diagnóstico de mieloma múltiple.

$\triangleright$ El diagnóstico de mieloma múltiple no secretor depende de la sospecha clínica.

$\triangleright$ Las fracturas múltiples de huesos planos suponen un dato de alarma.

\section{Introducción}

El mieloma múltiple (MM) se define como una proliferación clonal de células plasmáticas. Estas células, en condiciones fisiológicas, son capaces de sintetizar y secretar anticuerpos, los cuales están formados por cadenas pesadas que determinan su isotipo (IgG, IgA, IgM, IgE, IgD) y cadenas ligeras (kappa y lambda). Cada clon fisiológico de células plasmáticas produce una determinada inmunoglobulina y una pequeña cantidad de cadena ligera libre (CLL).
Según la capacidad secretora del MM, consideramos tres grupos: secretor de inmunoglobulinas completas (85\%), secretor de cadenas ligeras o de Bence Jones (15\%) y no secretor (<1\%). El proteinograma en suero detecta generalmente un pico monoclonal en los secretores de inmunoglobulinas intactas, mientras que el proteinograma en orina es más útil en los secretores de cadenas ligeras, si bien, en la actualidad se determinan niveles de cadenas ligeras libres en suero.

Un escaso número de MM no secretan el componente monoclonal (verdaderos no secretores) o ni siquiera pueden sintetizarlo (no productores) ${ }^{1,2}$. La expansión clonal suele afectar a la médula ósea de forma difusa, aunque puede organizarse en masas denominadas plasmocitomas. El daño óseo ocasiona una osteoporosis secundaria con dolor óseo asociado, hipercalcemia y anemia normocítica'. En casos de afectación severa pueden sucederse fracturas patológicas y agravarse las citopenias secundariamente a la infiltración medular. La insuficiencia renal viene favorecida en mayor medida por la eliminación de cadenas ligeras («riñón del mieloma»). 
En la práctica clínica, la principal sospecha se establece con la presencia de síntomas CRAB (hipercalcemia, insuficiencia renal, anemia y lesiones óseas) y la consecuente realización de un proteinograma con pico monoclonal (en suero u orina). El diagnóstico se confirma con la obtención de muestra de médula ósea con al menos un $10 \%$ de células plasmáticas clonales ${ }^{3}$ (Tabla 1).

Células plasmáticas (CP) clonales en médula ósea $\geq 10 \%$ o biopsia confirmatoria de plasmocitoma óseo o extramedular y cualquiera de los siguientes eventos:

\begin{tabular}{|c|c|}
\hline Daño orgánico (CRAB) & Marcadores particulares \\
\hline \multirow{3}{*}{$\begin{array}{c}\text { HiperCalcemia } \\
\text { Insuficiencia Renal } \\
\text { Anemia } \\
\text { Lesiones óseas } \\
\text { (Bone disease) }\end{array}$} & CP clonales en médula ósea $\geq 60 \%$ \\
\hline & $\begin{array}{l}\text { Cadenas ligeras libres (ambos): } \\
\text { • } \quad \text { CLL alterada/no-alterada } \geq 100 \\
\text { - } \quad \text { CLL alterada } \geq 100 \mathrm{mg} / \mathrm{L}\end{array}$ \\
\hline & Estudio RM con > 1 lesión focal \\
\hline
\end{tabular}

Tabla 1. Criterios diagnósticos de mieloma múltiple (IMWG, 2014).

La ausencia de pico monoclonal en el MM no secretor, un hecho excepcional, puede ocasionar un retraso en el diagnóstico y ensombrecer el pronóstico, aun cuando su tratamiento y supervivencia podrían superponerse al MM secretor.

\section{Caso clínico}

\section{Antecedentes personales}

Mujer de 76 años de raza caucásica. Sin alergias medicamentosas. Exfumadora. Cardiopatía isquémica. Lumbalgia crónica en relación con espondilosis, escoliosis y aplastamientos osteoporóticos lumbares. Gammagrafía con depósitos patológicos en costillas y columna sugestivos de origen osteoporótico. Cirugías previas: cifoplastia D12, artrodesis L4-L5.

Tratamiento habitual: ácido acetilsalicílico, bisoprolol, atorvastatina, pantoprazol, mirtazapina, oxicodona/naloxona, pregabalina, calcio, vitamina D, alendronato.

Situación basal: dependiente para actividades básicas. Deambula con andador. No deterioro cognitivo. Vive con su familia.

\section{Enfermedad actual}

La paciente acudió a Urgencias hospitalarias por empeoramiento de lumbalgia crónica con imposibilidad para la deambulación en los últimos días. Asociaba hiporexia y astenia más intensas respecto sus habituales, que sus familiares relacionaban con agudización de dolor crónico. No refirieron caídas, traumatismos, clínica miccional ni fiebre.

\section{Exploración física}

- Mal aspecto. Caquéctica. Palidez mucocutánea.

- Auscultación cardíaca: rítmica, sin soplos.

- Auscultación pulmonar: hipofonesis, sin ruidos sobreañadidos.

- Abdomen: blando, no doloroso, sin masas, ruidos normales.

- Extremidades: no se aprecian edemas ni signos de trombosis.

\section{Pruebas complementarias}

- Analítica de sangre. Leucocitos $7.340 / \mathrm{mm}^{3}$ (3.600-10.500) con fórmula normal, hemoglobina 8,9 g/dL (11,8-15,8), VCM 99 fl (80-101), plaquetas 156.000/mm3 (140.000-370.000); INR 1,06; creatinina 1,28 mg/dL (0,5-1,1), urea $117 \mathrm{mg} / \mathrm{dL}$ (20-50), potasio 5,1 mEq/L (3,5-5,3), ácido úrico 8,3 mg/dL (1,9-7,5), proteínas totales 4,9 g/dL (5,7-8,2), albúmina 3,0 g/dL (3,2-4,8), calcio corregido 10,3 (8,6-10,2), bilirrubina 0,3 mg/dL (0,3-1,2), LDH $304 \mathrm{U} / \mathrm{L}$ (120-246), GPT 18 U/L (10-49), GOT 19 U/L (0-37), GGT 36 U/L (0-38), proteína C reactiva $32 \mathrm{mg} / \mathrm{L}$ (0-5). Vitamina B12 $460 \mathrm{pg} / \mathrm{mL}$ (211-911), ácido fólico 7,4 ng/mL (3,4-10), ferritina $365 \mathrm{ng} / \mathrm{mL}$ (10-120). TSH 0,16 (0,35-5,5), T4 libre 1,50 ng/dL (0,77-1,76). Proteinograma: no se observa componente monoclonal. Cadenas ligeras libres: indetectables.

- Orina de 24 horas. 0,08 g proteínas/24 horas (0,0-0,1).

- Radiografía de tórax. Osteopenia. Callos de fractura en ambas parrillas costales.

- Radiografía de pelvis. Osteopenia. Callos de fractura en rama ileopubiana e isquiopubiana derechas.

- Radiografía de columna lumbar. Fracturas vertebrales desde T12 hasta L5.

- Resonancia magnética (RM) cervical y lumbar. Cambios degenerativos en cuerpos vertebrales. Sin datos de mielopatía compresiva. Material de osteosíntesis.

- Frotis de sangre periférica. Cuadro leucoeritroblástico (anisopoiquilocitosis, dacriocitos, plaquetas grandes y dismórficas).

- Mamografías y ecografía mamaria. Sin lesiones.

- Tomografía computarizada (TC) toraco-abdomino-pélvica con contraste. Patrón apolillado difuso en esqueleto axial con aplastamientos vertebrales múltiples.

- Biopsia de médula ósea. Amplia infiltración (95\%) por células plasmocitoides marcadamente atípicas con pseudoinclusiones y nucleolos. En el estudio inmunohistoquímico muestran intensa positividad de membrana para CD38, mostrándose negativas para anticuerpos frente a cadenas ligeras kappa y lambda, CD20, marcadores epiteliales (AE1-AE3) y melánicos (MelanA), confirmándose que se tratan de células plasmáticas atípicas.

\section{Evolución}

Se realizó estudio para descartar complicación medular o radicular a través de RM cervical y lumbar, sin hallazgos relevantes. En la valoración diaria en planta, el dolor óseo difuso, la hiporexia y una consunción evidente dominaban el cuadro clínico. Ante anemización progresiva $(\mathrm{Hb} 8,0 \mathrm{~g} / \mathrm{dL})$ y trombopenia de nueva aparición $\left(88.000 / \mathrm{mm}^{3}\right)$, se realizó extensión de sangre periférica observándose cuadro leucoeritroblástico, planteando diagnóstico diferencial de ocupación medular ${ }^{4}$.

La ausencia de pico monoclonal hasta ese momento, dirigió el diagnóstico diferencial a otras posibilidades diferentes al MM, principalmente: mielofibrosis y carcinoma sólido metastásico. Se descartó esplenomegalia en ecografía, haciendo poco probable la mielofibrosis primaria. Asimismo, se realizó biopsia de médula ósea en cresta iliaca anterior tras intento infructuoso en cresta posterior. El hueso presentaba una consistencia muy friable sospechosa de malignidad, considerándose a priori carcinoma de mama o pulmón por su frecuente metastatización ósea.

Se realizó estudio mamario dentro de la normalidad y TC torácico-abominopélvico, describiendo patrón apolillado en costillas, vértebras y huesos pélvicos (Figura 1); no se encontraron lesiones pulmonares. La realización de biopsia de médula ósea (Figura 2) confirmó el diagnóstico de mieloma múltiple no secretor. 

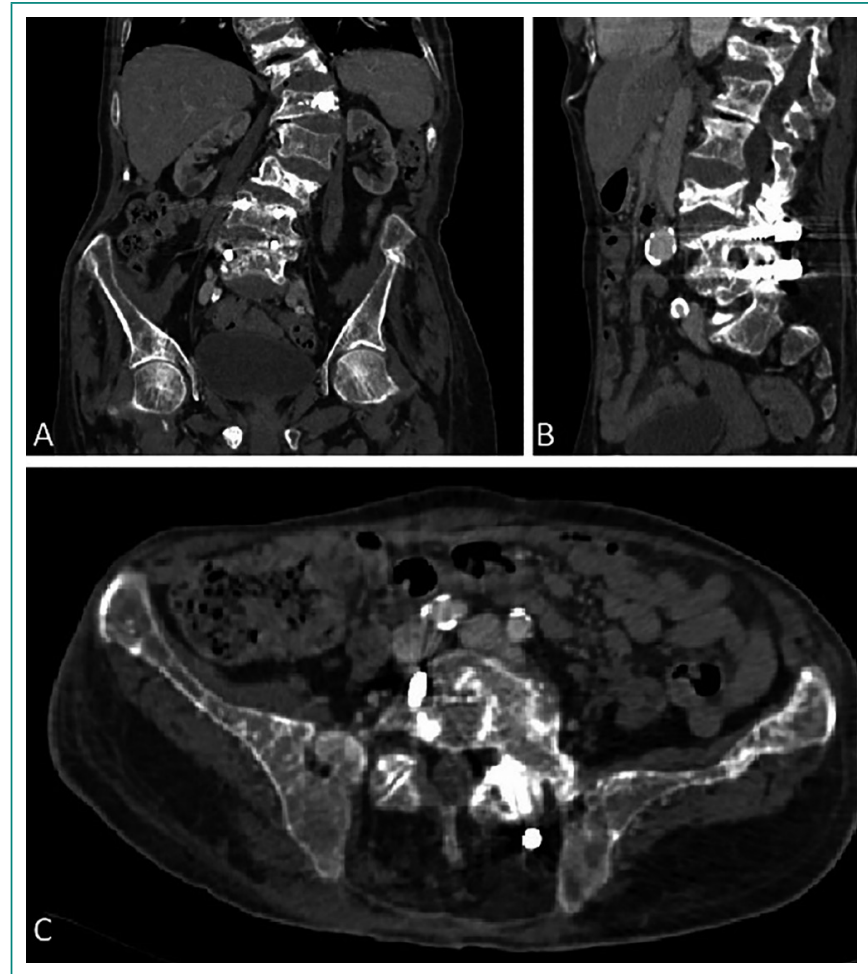

Figura 1. Múltiples aplastamientos vertebrales (A y B) con patrón apolillado difuso que alterna zonas escleróticas y osteopénicas (A, B y C).

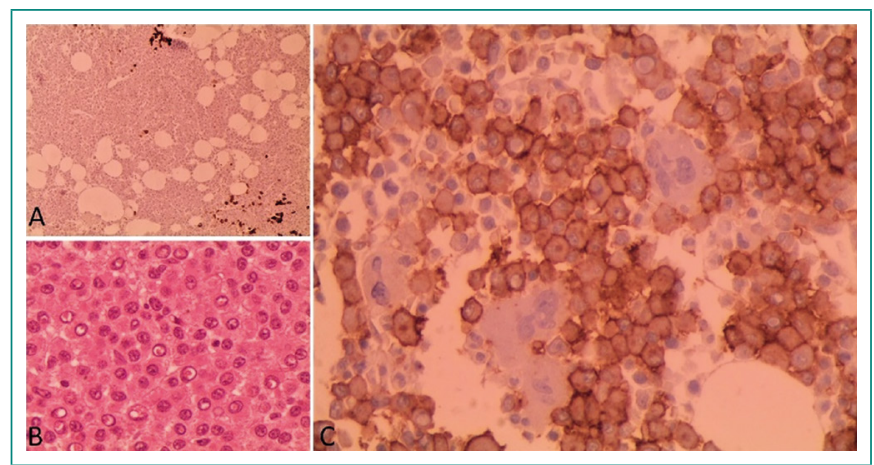

Figura 2. Infiltración masiva por celularidad neoplásica con escasa celularidad hematopoyética (A). Atipia celular marcada con pseudoinclusiones y nucleolos (B). La inmunohistoquímica para CD38 resulta intensamente positiva en la celularidad neoplásica (C).

La paciente presentaba situación de caquexia oncológica y dependencia para las actividades básicas, por lo que se consideró fútil, incluso deletéreo, el tratamiento quimioterápico. Como parte del manejo paliativo para mejorar su calidad de vida y controlar el dolor óseo se administró ácido zoledrónico 4 mg mensual y dexametasona $4 \mathrm{mg}$ diarios, lo que permitió reducir la dosis de opioides y facilitar las transferencias.
Diagnóstico

Mieloma múltiple no secretor.

\section{Discusión y conclusión}

El MM no secretor es una variante de mieloma excepcional. La ausencia de pico monoclonal en el proteinograma de sangre y orina condiciona un diagnóstico dificultoso, basado fundamentalmente en la sospecha clínica. Pese a centrar nuestra atención en la búsqueda de MM, resulta importante recordar que la existencia de pico monoclonal no es un criterio diagnóstico ${ }^{3}$ (Tabla 1).

Un dato particular que podría ayudar a diferenciar osteoporosis primaria (posmenopáusica y senil) de secundaria a otras patologías es el tipo de huesos afectos. En la osteoporosis primaria suelen afectarse huesos esponjosos sometidos a carga, como las vértebras, mientras que las lesiones en huesos planos no sometidos a carga, especialmente si son múltiples, resultan sospechosas ${ }^{5}$. El dolor óseo difuso en zonas sin fractura, también resulta alarmante.

De esta forma, ante una sospecha alta de mieloma, con síntomas CRAB y especialmente si existe cuadro consuntivo, debemos valorar la obtención de muestra de médula ósea con independencia de la presencia de pico monoclonal. Así, evitaremos demorar el diagnóstico y podremos mejorar la supervivencia de estos pacientes.

Para concluir, el caso expuesto también resalta la importancia de prestar cuidadosa atención a la información que aportan paciente y familiares, ya que cuadros crónicos como una lumbalgia, pueden reorientarse y finalmente ser debidos a entidades previamente no sospechadas o incluso descartadas.

\section{Bibliografía}

1. Dupuis MM, Tuchman SA. Non-secretory multiple myeloma: from biology to clinical management. Onco Targets Ther. 2016; 9: 7583-7590. doi: 10.2147/OTT.S122241.

2. Corso A, Mangiacavalli S. Non-Secretory Myeloma: Ready for a new Definition? Mediterr J Hematol Infect Dis. 2017; 9(1): e2017053. doi: 10.4084/ MJHID.2017.053.

3. Rajkumar SV, Dimopoulos MA, Palumbo A, Blade J, Merlini G, Mateos MV, et al. International Myeloma Working Group updated criteria for the diagnosis of multiple myeloma. Lancet Oncol. 2014; 15(12): e538-48. doi: 10.1016/ S1470-2045(14)70442-5.

4. Tabares Calvache E, Tabares Calvache AD, Faulhaber GAM. Systematic review about etiologic association to the leukoerythroblastic reaction. Int J Lab Hematol. 2020 Jun 20. doi: 10.1111/ijlh.13238.

5. Mosebach J, Thierjung H, Schlemmer HP, Delorme S. Multiple Myeloma Guidelines and Their Recent Updates: Implications for Imaging. Rofo. 2019; 191 (11): 998-1009. doi: 10.1055/a-0897-3966. 